Article

\title{
Incidental Exposure to Non-Like-Minded News through Social Media: Opposing Voices in Echo-Chambers' News Feeds
}

\author{
Pere Masip *, Jaume Suau and Carlos Ruiz-Caballero
}

Blanquerna School of Communication and International Relations, Ramon Llull University, 08001 Barcelona, Spain; E-Mails: peremm@blanquerna.url.edu (P.M.), jaumesm@blanquerna.url.edu (J.S.), carlesrc@blanquerna.url.edu (C.R.)

* Corresponding author

Submitted: 14 April 2020 | Accepted: 5 June 2020 | Published: 8 October 2020

\begin{abstract}
Debates about post-truth need to take into account how news re-disseminates in a hybrid media system in which social networks and audience participation play a central role. Hence, there is a certain risk of reducing citizens' exposure to politically adverse news content, creating 'echo chambers' of political affinity. This article presents the results of research conducted in agreement with 18 leading Spanish online news media, based on a survey $(N=6625)$ of their registered users. The results highlight that high levels of selective exposure that are a characteristic of offline media consumption are being moderated in the online realm. Although most of the respondents get news online from like-minded media, the figures related to those who also get news from media with a different media ideology should not be underestimated. As news consumption is becoming more 'social,' our research points out that Spanish citizens who are more active on social media sites are more likely to be exposed to news content from different ideological positions than those who are less active users. There is a weak association between the use of a particular social network site and gaining access to likeand non-like-minded news.
\end{abstract}

\section{Keywords}

incidental exposure; news consumption; polarization; selective exposure; social media; Spain

\section{Issue}

This article is part of the issue "The Ongoing Transformation of the Digital Public Sphere" edited by Emiliana De Blasio (LUISS University, Italy), Marianne Kneuer (Hildesheim University, Germany), Wolf J. Schünemann (Hildesheim University, Germany) and Michele Sorice (LUISS University, Italy).

(C) 2020 by the authors; licensee Cogitatio (Lisbon, Portugal). This article is licensed under a Creative Commons Attribution 4.0 International License (CC BY).

\section{Introduction}

Although positive discourses have dominated academic views about how Internet-related technologies may affect life in democratic societies (Curran, Fenton, \& Freedman, 2012), in recent years we have seen a growing concern regarding their potential for pernicious effects (Sunstein, 2018). Concerns relate to the potential lack of exposure to politically divergent ideas, which might deprive citizens of the alternative viewpoints they need for deliberation and decision-making, and cause western democracies to become less informed (Sunstein, 2009) and less tolerant to opposing views (Jamieson \& Cappella, 2008). Rather than contributing to the creation of democratically necessary agonistic spaces in which dialogue and understanding of 'the others' might happen (Mouffe, 2013; Ruiz et al., 2011), it seems that online environments are promoting the isolation of citizens within small like-minded groups (Sunstein, 2018) or 'solo spheres' (Dahlgren, 2013). The recent controversy about how easily fake news spreads within Western societies (Balmas, 2014; Khaldarova \& Pantti, 2016) seems to reinforce the theories that defend that citizens are nowadays more capable of filtering the nature and origin of the information they consume, being more likely to be exposed to like-minded information rather than neutral or antagonistic points of view (Colleoni, Rozza, \& Arvidsson, 2014). From a twentieth-century media 
landscape in which incidental exposure to news was frequent, it seems that we have been moving towards a post-broadcast era characterised by a high-choice media environment in which possibilities for selective exposure have been constantly expanding (Prior, 2007). Despite this evidence, recent research has also found that some online spaces such as social media might have a positive effect in undermining the effects of selective exposure mechanisms (Flaxman, Goel, \& Rao, 2016), creating incidental ways by which citizens might make contact with opposing points of view or political perceptions (Bakshy, Messing, \& Adamic, 2015; Barbera, Jost, Nagler, Tucker, \& Bonneau, 2015). This article aims to contribute to these discussions by studying if social media use increases Spanish citizens' exposure to non-like-minded news. Although selective exposure to traditional news has been researched in the country (Humanes, 2016), there is a gap in research about the particular effects of social media. Moreover, we will focus also in analysing the effects of different platforms on accidental exposure, rather than just studying social media in general terms. Our survey-based research points towards the existence of echo chambers within Spanish social media; however, Twitter and Facebook present different results, the former being more likely to facilitate access to ideologically challenging content. In order to better present these findings, our article will start with an analysis of current research on selective and incidental exposure, continuing then to introduce the methodology used and the findings. The article concludes with a discussion about the relevance of our findings in relation to the existing literature in the field.

\section{Selective Exposure and the New Media Environment}

The nature of the new media environment (Press \& Williams, 2010) and how it might have transformed behavioural patterns of media consumption have been issues of great interest in media studies in recent decades (Knobloch-Westerwick, Johnson, \& Westerwick, 2013; Mitchelstein \& Boczkowski, 2010; Schrøder, 2015). Among these, a topic that has attracted a great deal of interest in academia is the study of the effects of the Internet on the distribution and consumption of news media. In a media system dominated by broadcasted and printed news media (Prior, 2007), there was a general agreement about the extent to which media consumption and selective exposure were operating. Developed several decades ago (Lazarsfeld, Berelson, \& Gaudet, 1948; Zillmann \& Bryant, 1985), selective exposure theory argues that citizens tend to choose among the media landscape the news content that matches their political and ideological positions. Several authors have proved that thanks to the diversification of media choices in a post-broadcast era (Prior, 2007) it has become easier for citizens to avoid non-like-minded information about public affairs (Bennett \& lyengar, 2008; lyengar \& Hahn, 2009). Balancing selective exposure mechanisms, former research has also found traces of incidental exposure or balanced exposure (Lacour, 2015; Newman, Fletcher, Kalogeropoulos, Levy, \& Nielsen, 2017), behavioural patterns that might allow citizens to avoid the pernicious effects of selective exposure through consumption of non-like-minded news or non-biased information. Furthermore, although admitting the importance of selective exposure mechanisms, some other authors point out that this is more pronounced just for those citizens who are already engaged or highly politically active (Prior, 2013; Stroud, 2011).

The widespread adoption of the Internet as well as online spaces such as social media sites, however, has recently brought some new debates to the table. The patterns of cross-media consumption (Schrøder, 2015) and the hybridity of the media system (Chadwick, 2013) that characterize the new media environment are challenging the traditional common understanding of how citizens receive news. Consequently, although some audiences are still more engaged with traditional news media (and therefore, their patterns of media consumption and selective exposure are similar to those of some decades ago), some other sectors of the audience use social media in a way that is challenging formerly established theories in media studies, such as selective exposure.

Regarding selective exposure theory, some authors follow Sunstein's fears $(2002,2018)$ about the pernicious effects that the use of new communication technologies might have in democratic life. Recent research has shown how the Internet could be cultivating homophily between like-minded citizens (Colleoni et al., 2014), reinforcing selective exposure mechanisms. As citizens are increasingly adopting social media sites as a relevant source of news, the question of how this affects the diversity of media consumption and exposure to non-like-minded news has become ever more relevant (Newman et al., 2017; Sunstein, 2018). A particular effect of these trends might be the promotion of echo chambers or 'solo spheres' that could result in citizens only consuming news content which is in line with their existing political positions or ideological values (Jamieson \& Cappella, 2008; Pariser, 2011). Working on the assumption that citizens group in social media with like-minded people and share content in relation to their political beliefs, some authors have proposed that the public sphere could become divided into several smaller spheres in which diversity of points of views is absent (Dahlgren, 2013). This would suggest there is a risk of citizens' consumption of non-desired or politically adverse news content being limited, which could present a serious threat if society became so divided that citizens were isolated from spaces to meet 'the others' who might have different points of view (Mouffe, 2013). By only engaging with like-mined citizens, these 'private' or 'solo' spheres can make it easier for individuals to be manipulated by political elites or partisan news media, as well as making it easier for fake news to be disseminated (Bakshy et al., 2015; Khaldarova \& Pantti, 2016) as proven by the recent scandal involving Cambridge Analytica. 
Regarding news' dissemination on social networks, two key issues need to be addressed. Firstly, although social networks sites do not publish their algorithms, the systems that decide what we can 'see' in our timelines, it is known that Facebook prioritizes content shared by friends or family with whom we tend to interact more, rather than content shared by journalists or news media. Therefore, these sites prioritize the creation of filterbubbles (Pariser, 2011) in which citizens receive information according to pre-established algorithms designed to attract their attention, prioritizing the content that we are more likely to agree with or to like more. Citizens seem to have no say in the nature of the information received or the configuration of the algorithms.

On the other hand, in the measure that social networks have become one of the main sources of news (Newman et al., 2017), contacts on social networks such as Facebook are now highly relevant as 'secondary gatekeepers' (Singer, 2013), increasing their importance in news' dissemination and transforming the ways in which citizens receive informative content (Guallar, Suau, Ruiz-Caballero, Sáez, \& Masip, 2016). This forces news media to engage in an unfair 'battle for attention' against content selected and filtered by citizens (Thorson \& Wells, 2016), who normally publish on social networks a mix of informative and entertainment formats. Hence, competition for users' attention is then fierce for information providers, who need to compete against each other but also against entertainment formats (Davenport \& Beck, 2001; Lanham, 2006), forcing them to adopt formats that might catch quickly the attention of citizens surfing the web or checking news feeds on a social network (Klinger \& Svensson, 2015). Consequently, the main objective for the news media is that their stories attract a high level of attention to cause users to share them, making it more likely that they will spread around audiences' news feeds (Anspach, 2017). In the end, it is the common user who has the 'power' to decide to share the content, and thus control over the content's degree of dissemination. According to authors such as Sunstein (2018), a system of news' distribution that allocates such a great power on citizens is more likely to produce echo chambers and reinforce the consumption of like-minded news. Moreover, such a system also reinforces political polarization, as it prioritizes content shared by those closest to us whose political positions and values we normally tend to agree with.

\section{Towards a Positive Approach}

Although some parts of the academic literature on the subject are cautious or pessimistic about the effects of social networks on the dissemination of news content, and its implications for public opinion and democratic life, there are also some more positive voices (Bakshy et al., 2015; Boxell, Gentzkow, \& Shapiro, 2017). A recent report pointed out that Internet users are more likely to be exposed to non-like-minded news rather than tend- ing to avoid such information that might challenge their political beliefs (Newman et al., 2017). Other authors also disagree about these fears, contributing with recent research that actually points towards mechanisms that favour incidental exposure rather than selective exposure (Dubois \& Blank, 2018; Flaxman et al., 2016; Garrett, 2009; Lacour, 2015).

The point of discussion is to determine if social networks, rather than increasing the effects of selective exposure, are, in fact, generating environments in which incidental exposure to political differences is more "likely to occur, at least on occasion, whether or not it is explicitly selected" (Brundidge, 2010, p. 696). Some authors adopt a positive understanding of the role of social media in news consumption, pointing out how online spaces mix entertainment and informative content. Previous research argued that this characteristic of social networks might positively affect news exposure: even those citizens who are more disengaged with news and normally access social media for entertainment purposes are more likely to be exposed to information about public issues (Mitchell, Kiley, Gottfried, \& Guskin, 2013). Despite being informed about public events, a kind of content that they would normally never or barely access, the fact that they have other citizens among their contacts who do access and share this content might aid in exposing them to news, even if these are from an opposite ideological source or point of view (Bakshy et al., 2015; Barbera et al., 2015).

A series of studies conducted in the United States by the Pew Research Center (Holbert, Garrett, \& Gleason, 2010; Mitchell, 2014) point in this direction, with social media users from the USA more likely to report being exposed to a high number of publications that challenge their political positions or ideological values. It seems then that contacts in online environments such as social networks are not ideologically closed spaces and that citizens have others among their contacts who maintain politically relevant ideological discrepancies (Purcell, Rainie, \& Mitchell, 2010). Following this point, according to Garrett (2009), there is no evidence that when a citizen is exposed to non-like-minded news they will avoid it in greater measure than ideologically affine ones. Moreover, Garrett (2009), following biased-assimilation theory (Lord, Ross, \& Lepper, 1979; Munro et al., 2002) shows evidence that citizens are more likely to spend more time analysing information that challenges their political perceptions and values. If this is the case, social media might promote a more varied diet of news sources and political positions than more traditional means of news consumption (Baresch, Knight, Dustin, \& Yaschur, 2011; Messing \& Westwood, 2012).

\section{Aims and Methodology}

In order to contribute to these debates, this article presents data gathered from users registered on Spanish news sites. Results follow a line of research that points 
towards a more complex understanding of the role of social media in selective exposure and news consumption in a country characterized by a polarized media system (Hallin \& Mancini, 2004; Newman et al., 2017). Previous research (Humanes, 2016; Valera-Ordaz, 2018) has shown how in Spain there is evidence of selective exposure, driven by political affinity, in news consumption through traditional media. More specifically, it seems that it is newspapers that have higher levels of selective exposure, with Spanish newspapers being affiliated with political parties and/or political positions (Humanes, 2014). This is in line with the nature of the political and media system: Being part of the polarized pluralist model Spain has, among other characteristics, a higher identification of news media with political ideologies and/or political parties. Consequently, in their media choices, citizens tend to choose those news media that reinforce or defend their political positions (Roses, 2011). Previous research into television and radio has also identified patterns of selective exposure, albeit to a lesser degree than in press consumption (Humanes, 2014). These results are consistent with a media system, like the Spanish one, which has several problems of pluralism, as the Media Pluralism Monitor (MPM) reflects. According to the results obtained by the MPM, the Spanish media system has a highly partisan news media, with strong connections between the media and political and economic elites (Masip, Ruiz, \& Suau, 2017). Consequently, in such a highly polarized media landscape, citizens are affected by a lack of incidental exposure to content that might challenge their political positions or beliefs (Masip, Suau, \& Ruiz, 2018).

Previous research has been focused on legacy media, however it has not addressed the influence of social networks sites on selective exposure. Recent data from the Spanish Statistics Institute shows that around eight in ten Spaniards regularly use the Internet and among those $86 \%$ use social networks (Newman, Fletcher, Kalogeropoulos, \& Nielsen, 2019). There is a need then to assess if those citizens who are more active online show different patterns of selective exposure than the general public studied in previous research. Therefore, our first research question is as follows:

RQ1. Does the level of social media use favour access to non-like-minded news, thus limiting the effects of selective exposure?

Furthermore, there is also a need to start to differentiate among the effects on selective exposure of different social media sites (Dubois \& Blank, 2018). While $53 \%$ of the Spanish population accesses news through social media (Newman et al., 2019), with Facebook being the most popular social site for news (47\%), the use of WhatsApp is starting to rival it (36\%), and Twitter now has $16 \%$ of users. It is obvious that different social media are used in different ways. Intending to avoid generalizations of 'Internet use' (Hirzalla, van Zoonen, \& de Ridder, 2010), this research intends to focus on how the different social networks affect selective exposure. So far, previous research has normally focused on the effects of a particular social network, normally Twitter thanks to the ease of access to its data. Hence, our second research question is the following:

RQ2. To what extent does the use of a particular social network effect selective exposure and the pluralism of news consumption?

To answer the research questions a quantitative approach was selected, based on a survey of registered users of online news media which had a print counterpart. Registering was free of charge at the time of carrying out the survey, with registration allowing users to comment on news and access other features. The survey was possible thanks to a collaboration agreement with 18 Spanish news sites, all of them having a paper counterpart. The media outlets had a daily average circulation of more than 162,000 copies during the second half of 2016 and around 3,000,000 unique viewers.

A self-administered questionnaire, which contained 40 questions, was sent by e-mail to registered users in 2016. Media outlets did not provide the total number of registered users they had, nor their socio-demographic data. Hence, the final sample is not the result of a selection made by the researchers, but it includes those people who voluntarily accepted and decided to collaborate (self-selected). A total of 6,625 questionnaires were eventually returned. Given the number of responses collected, it is reasonable to expect that the results could represent a broad spectrum of registered users in the participating media. Demographics for the sample are provided in Table 1.

\section{Results}

We obtained 6,625 responses from users registered in news sites. Table 1 shows the demographics and Internet use of the participants. We had more male participants $(65.8 \%)$ than female (34.2\%). Age was grouped in categories, and the majority of participants being in the over 55 age range (46.63\%). Both genre and age are not representative of the Spanish population as a whole. However, demographic features are consistent with those of Spanish newspaper readers. Newspaper readers are mainly male $(60,7 \%)$ and older than 35 (35-54: 41.1\%; $\geq 55$ : 39.4\%).

Among participants, the Internet is the main source of news (57.6\%), and it is an important, although not the main source, for the other $40 \%$. Only $2.4 \%$ of the respondents did not use the Internet as their main source of news.

More than a half of respondents $(52.2 \%)$ are registered in a like-minded medium (30.2\%), or more than one $(22 \%)$, and $43.5 \%$ are registered in both like-minded and non-like-minded media. Surprisingly, $4.3 \%$ reported 
Table 1. Demographics and Internet and media use.

\begin{tabular}{|c|c|c|}
\hline & Response & $\mathrm{N}$ \\
\hline \multirow[t]{3}{*}{ Age } & Male & $4386(66.2 \%)$ \\
\hline & Female & $2239(33.8 \%)$ \\
\hline & Total & $6625(100 \%)$ \\
\hline \multirow[t]{5}{*}{ Age } & $16-24$ & $233(3.5 \%)$ \\
\hline & $25-34$ & 435 (6.6\%) \\
\hline & $35-54$ & $2867(43.3 \%)$ \\
\hline & $\geq 55$ & $30890(46.6 \%)$ \\
\hline & Total & $6625(100 \%)$ \\
\hline \multirow[t]{4}{*}{ Internet as a source of news } & Most important & $3254(53.7 \%)$ \\
\hline & Important, but secondary & $2581(42.6 \%)$ \\
\hline & Secondary and not important & $225(3.7 \%)$ \\
\hline & Total & $6060 *(100 \%)$ \\
\hline \multirow[t]{4}{*}{ Use of social networks } & Very often/Often & $1040(31.6 \%)$ \\
\hline & Sometimes & $1426(35.7 \%)$ \\
\hline & Rarely/Never & $1790(32.7 \%)$ \\
\hline & Total & $4256 *(100 \%)$ \\
\hline \multirow[t]{5}{*}{ Registered in } & A like-minded medium & $1572(33.23 \%)$ \\
\hline & More than one like-minded medium & $1131(23.91 \%)$ \\
\hline & Like-minded and non-like-minded medium & $1872(39.58 \%)$ \\
\hline & Only to non-like-minded medium & $155(3.28 \%)$ \\
\hline & Total & $4730 *(100 \%)$ \\
\hline
\end{tabular}

Note: * Valid responses.

that they had only registered in media with a different ideology.

That a majority of respondents are registered in like-minded media can be considered as foreseeable. However, it is remarkable that more than $40 \%$ of people surveyed are registered in non-like-minded media. These results indicate that the Internet could diminish the effects of selective exposure, contradicting authors such as Sunstein (2018) and lyengar and Hahn (2009), as it offers greater scope for accessing alternative points of view.

For this research, it is also interesting to underline that $67.3 \%$ of respondents use social media regularly, and $32.7 \%$ do not or scarcely use it. The average use of social networks is slightly lower than the Spanish population as a whole (70.3\%; IAB, 2017). These results can be explained by the overrepresentation of the over 55 age group, $48.3 \%$ of whom rarely or never use social media according to IAB data.

Overall, around two thirds (65.8\%) of respondents follow media outlets on social networks, and almost $50 \%$ also follow journalists. There is a direct relationship between the intensity of social network use and the following of news sites $\left(\chi^{2}=861.9617, \mathrm{df}=2, \mathrm{p}<.05\right)$ and journalists $\left(\chi^{2}=543.3126, d f=2, p<.05\right)$. Although this relationship is stronger for the media (Cramer's V $=0.450$ ) than for journalists (Cramer's V $=0.357$ ).
We also asked participants where they get their news from. As expected, the level of access to news media is higher regarding like-minded news media than non-likeminded. Based on a 5-point scale ( $5=$ Very frequently, $4=$ Frequently, 3 = Sometimes, $2=$ Rarely, $1=$ Never), $62 \%$ of respondents access like-minded media frequently or very frequently $(M=3.7, S D=1.23)$. Just $27 \%$ get news from non-like-minded sources frequently or very frequently. However, if the results are extended to those who also sometimes access non-like-minded media, the figure rises to $60.9 \%$ (Non-like-minded media: $M=2.8$, $\mathrm{SD}=1.22$ ).

Results show that commenting $(M=2.5, S D=1.4)$, sharing $(M=2.63, S D=1.49)$, and receiving $(M=2.81$, $S D=1.54)$ news, is much more frequent in the case of like-minded news media. For non-like-minded news media, the percentage of people who comment $(M=2.04$, $\mathrm{SD}=1.25)$, share $(\mathrm{M}=1.9$, SD $=1.2)$, or receive $(M=2.07, S D=1.2)$ news from these opposite point of view sources is only around $12-15 \%$, with the percentage increasing to $30 \%$ only if we include those who do this sometimes.

Degree of activity on social networks entails significant differences in both getting $\left(\chi^{2}=21.263, \mathrm{df}=4\right.$, $\mathrm{p}=0.000)$ and commenting on $\left(\chi^{2}=223.91, \mathrm{df}=4\right.$, $p=0.00001$ ) news from non-like-minded media (see 
Table 2. Chi-square test for independence.

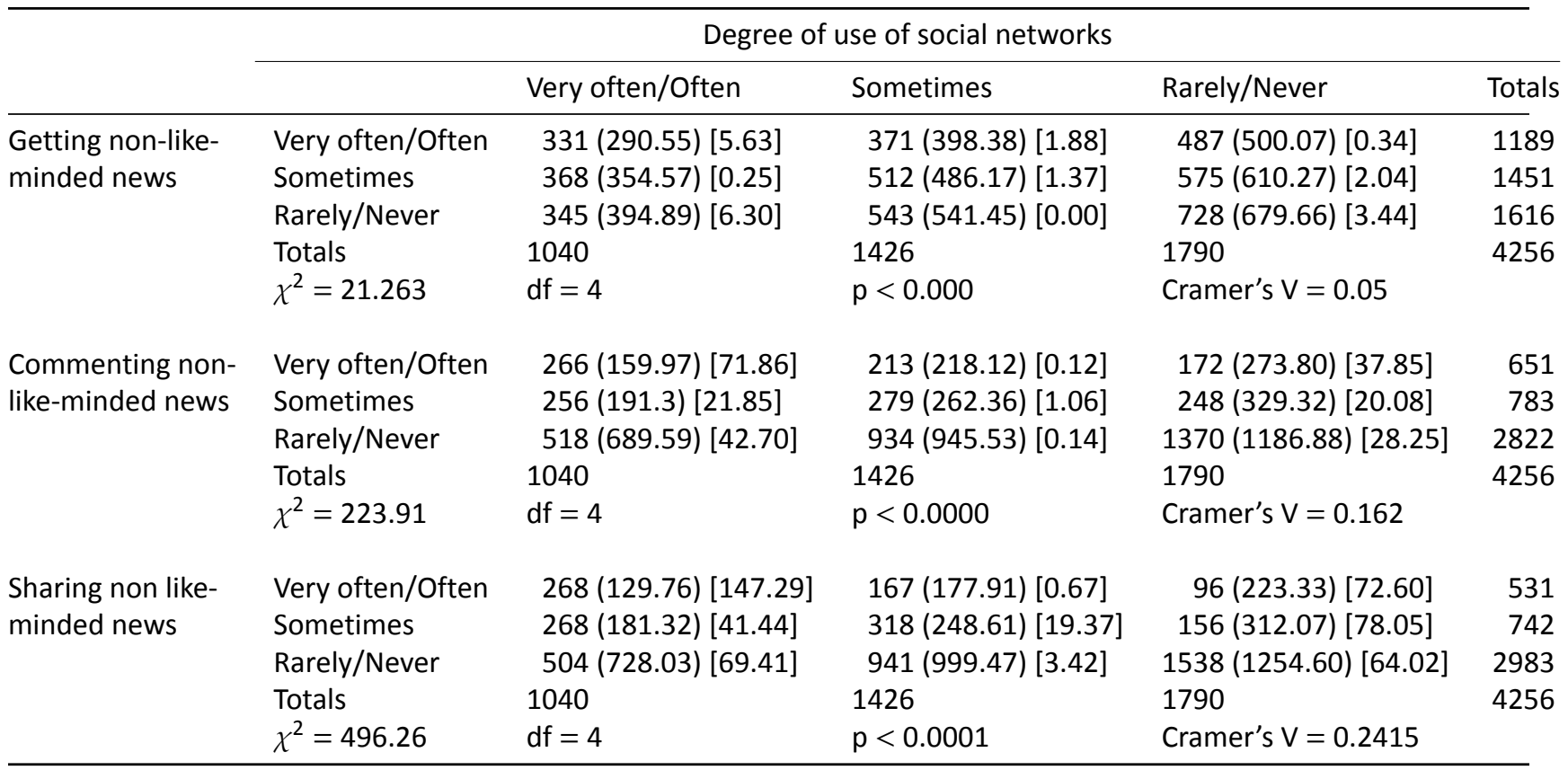

Table 2). Differences are more significant in what regards commenting on (Cramer's $\mathrm{V}=0.162$ ), than getting (Cramer's $V=0.05$ ) news. Contingency tables and $\chi^{2}$ tests show results that are poles apart. Among the respondents, those who use social media more frequently are more likely to get news from non-like-minded news media. In contrast, less frequent users of social networks are less exposed to politically adverse news content. This pattern is repeated regarding commenting on news, although the differences are stronger. Regarding the sharing of news on social media, differences are more evident than getting and commenting $\left(\chi^{2}=496.26, \mathrm{df}=4\right.$, $p=0.001$ ). Thus, active users of social networks are still more likely to share news from ideologically opposed positions (Cramer's V $=0.2415$ ).

In line with the results obtained by Newman et al. (2019), respondents tend to have Facebook as their most popular social network for getting news. However, it is also interesting to highlight the growing role of WhatsApp, which is already more used than Twitter to interact with news. Friends are the main diffusers of news, followed by media outlets (Table 3 ).

Results also show that there is an association between consuming news from like- or non-like-minded news media and the use of a particular social network. As shown in Table 4, the use of Facebook is connected to getting and sharing like-minded content. In contrast, Twitter is strongly connected to getting and sharing news from both like-minded and non-like-minded news media. The connection with non-like-minded news media is less strong than from like-minded media but stronger than the relationships of these variables in Facebook. Finally, there is no significant relationship between the use of WhatsApp and getting or commenting on news from likeminded or non-like-minded news media.

Table 3. Social networks used for getting/sharing/commenting news by sources.

\begin{tabular}{lcccc}
\hline & Facebook & Twitter & WhatsApp & Instagram \\
\hline Media outlets & $2059(25.5)$ & $1239(25.9)$ & $953(18.4)$ & $245(15)$ \\
Political parties, NGOs... & $1261(15.6)$ & $776(16.2)$ & $521(10.1)$ & $148(8)$ \\
Friends & $2482(30.7)$ & $938(19.6)$ & $2925(56.5)$ & $679(41.5)$ \\
Journalists & $860(10.6)$ & $847(17.7)$ & $213(4.1)$ & $137(8.4)$ \\
Celebrities & $304(3.80)$ & $285(5.90)$ & $75(1.4)$ & $200(12.2)$ \\
Non-professional journalists & $1119(13.8)$ & $706(14.7)$ & $492(9.5)$ & $227(13.9)$ \\
Total & $8085(100)$ & $4791(100)$ & $5179(100)$ & $1636(100)$ \\
\hline
\end{tabular}

Note: More than one response was possible. 
Table 4. Chi-square test for independence.

\begin{tabular}{|c|c|c|c|}
\hline \multirow[b]{2}{*}{ Activity } & \multicolumn{3}{|c|}{ Use of social networks and selective exposure } \\
\hline & Social network & $\chi^{2}$ & Cramer's V \\
\hline Getting news from like-minded media & Facebook & $\begin{array}{l}\chi^{2}=10.92927 \\
d f=1 p=0.000947\end{array}$ & 0.04437211 \\
\hline Getting news from non-like-minded media & Facebook & $\begin{array}{l}\chi^{2}=3.029262 \\
d f=1 p=0.0818\end{array}$ & - \\
\hline Getting news from like-minded media & Twitter & $\begin{array}{l}\chi^{2}=46.89763 \\
\mathrm{df}=1 \mathrm{p}=7.48 \mathrm{e}-12\end{array}$ & 0.0925307 \\
\hline Getting news from non-like-minded media & Twitter & $\begin{array}{l}\chi^{2}=14.80282 \\
d f=1 p=0.000119\end{array}$ & 0.05209271 \\
\hline Getting news from like-minded media & WhatsApp & $\begin{array}{l}\chi^{2}=3.085377 \\
d f=1 p=0.079\end{array}$ & - \\
\hline Getting news from non-like-minded media & WhatsApp & $\begin{array}{l}\chi^{2}=0.8117424 \\
\mathrm{df}=1 \mathrm{p}=0.368\end{array}$ & - \\
\hline Sharing news from like-minded media & Facebook & $\begin{array}{l}\chi^{2}=424.7293 \\
d f=1 p<2 e-16\end{array}$ & 0.2770362 \\
\hline Sharing news from non-like-minded media & Facebook & $\begin{array}{l}\chi^{2}=159.2166 \\
d f=1 p<2 e-16\end{array}$ & 0.1701038 \\
\hline Sharing news from like-minded media & Twitter & $\begin{array}{l}\chi^{2}=250.198 \\
\mathrm{df}=1 \mathrm{p}<2 \mathrm{e}-16\end{array}$ & 0.2126289 \\
\hline Sharing news from non-like-minded media & Twitter & $\begin{array}{l}\chi^{2}=95.33175 \\
d f=1 p<2 e-16\end{array}$ & 0.1313093 \\
\hline
\end{tabular}

\section{Conclusions}

Results presented in this article offer some relevant insights concerning the debates around whether the Internet and social networks contribute to greater chances for selective exposure or if, conversely, they offer possibilities for incidental exposure to nonlike-minded news (Knobloch-Westerwick et al., 2013; Mitchelstein \& Boczkowski, 2010; Schrøder, 2015). Our research goes in line with the body of research that interprets the effects of social networks in news selection and distribution as being positive (Flaxman et al., 2016; Garrett, 2009; Lacour, 2015), contributing to the discussion by showing results from Spain and adding some relevant nuances that we will discuss further in this section.

These results are encouraging in the Spanish context, insofar as they open the door for greater exposure to challenging content. In this sense, social media sites could provide a degree of balance within a highly polarized media system which suffers from a lack of pluralism (Masip et al., 2018). This has been reflected by a high level of distrust towards journalists and traditional news media institutions (Newman et al., 2017). Not surprisingly, former research (Humanes, 2016) has shown high levels of citizens' selective exposure regarding traditional news media (press, television, and radio stations). Nevertheless, the effects in Spain of online environments such as social networks on pluralism and selective exposure had not yet been deeply analysed before this article.

Our research shows how these high levels of selective exposure that are characteristic of offline media consumption are being moderated in the online realm. Although most of the respondents are mainly registered with and get their news from like-minded media, the figures related to those who also get news from media with a different ideology should not be underestimated. According to our findings, most of our respondents access non-like-minded media at least 'sometimes' (60.9\%), but $27 \%$ do so frequently or very frequently. If social networks are taken into account, we found a direct relationship between higher use of these online spaces and a higher reception of non-like-minded news. Therefore, we can affirm that social media use increases the chances of incidental exposure to news from diverse political and ideological views (RQ1). This relationship is stronger in those activities that entail a higher degree of commitment and active attitude (sharing and commenting) rather than those that could be considered as a more passive activity (receiving news in the newsfeed and Timeline). In this sense, our findings support previous literature that defends the positive effects that social media might have in moderating selective exposure (Bakshy et al., 2015; Boxell et al., 2017; Dubois \& Blank, 2018). Moreover, our findings also refute recent 
claims about the relevance of echo chambers or filter bubbles: although this might be true for some citizens, most Spaniards do not inhabit such online environments of ideological affinity.

Regarding the second research question, we found that there is an association between the use of a particular social network site and gaining access to like- and non-like-minded news. However, this association is weak. While Facebook is connected to getting news with a similar ideological position, Twitter allows users to access both dissenting and consenting information. The difference could be related to the effects of algorithms in Facebook's news-stream (Pariser, 2011), which limit the exposure to conflicting viewpoints or to the different nature of the contacts in these two social networks. Further research on the impact of age on the results is also needed, as the over 55 age group is overrepresented within our sample. It is worth noting that older generations access social media less frequently than other age groups, although they do get news more frequently.

To conclude, in a media system such as the Spanish one, characterized by polarization and news media partisanship, citizens have typically been highly affected by a lack of incidental exposure to content that might challenge their political positions or beliefs. Our findings contribute to a better understanding of how elements of the hybrid media system, such as social media, affect traditional patterns of selective and incidental exposure. It seems that Spain could provide evidence against the echo-chamber theory, as Spanish citizens more active in social networks such as Facebook or Twitter are more likely to be incidentally exposed to non-like-minded content. However, the conclusions of this research are limited, as exposure to non-like-minded content is just a first step. Discussion, engagement, and efforts to understand the others' position are also key elements of a healthy democracy. Although exposure to others' opinions is needed, there is no proof that it alone can generate a less polarized society. Further research has to address the role of social networks in shaping Spanish society, especially regarding issues where citizens' views are polarized over a contested political issue that has divided society. Hence, our research points towards an interesting future line of research: The effects that exposure to non-like-minded media has in shaping or influencing citizens' existing views or political positions.

\section{Acknowledgments}

This work was supported by the Ministerio de Ecomomía y Competitividad (Spain) under grants CSO2015-64955C4-1-R (MINECO/FEDER) and Ministerio de Ciencia, Innovación y Universidades (Spain) RTI2018-095775-BC44.

\section{Conflict of Interests}

The authors declare no conflict of interests.

\section{References}

Anspach, N. (2017). The new personal influence: How our Facebook friends influence the news we read. Political Communication, 34(4), 1-17.

Bakshy, E., Messing, S., \& Adamic, A. (2015). Exposure to ideologically diverse news and opinion on Facebook. Science, 348(6239), 1130-1132.

Balmas, M. (2014). When fake news becomes real. Communication Research, 41(3), 430-454.

Barbera, P., Jost, J., Nagler, J., Tucker, J., \& Bonneau, R. (2015). Tweeting from left to right: Is online political communication more than an echo chamber? Psychological Science, 26(10), 1531-1542.

Baresch, B., Knight, L., Dustin, H., \& Yaschur, C. (2011). Friends who choose your news: An analysis of content links on Facebook. ISOJ: The Official Research Journal of International Symposium on Online Journalism, 1(2), 65-85.

Bennett, W., \& lyengar, S. (2008). A new era of minimal effects? The changing foundations of political communication. Journal of Communication, 58(4), 707-731.

Boxell, L., Gentzkow, M., \& Shapiro, J. (2017). Is the Internet causing political polarization? Evidence from demographics (NBER Working paper No. W23258). Cambridge, MA: National Bureau of Economic Research.

Brundidge, J. (2010). Encountering 'difference' in the contemporary public sphere: The contribution of the Internet to the heterogeneity of political discussion networks. Journal of Communication, 60(4), 680-700.

Chadwick, A. (2013). The hybrid media system: Politics and power. Oxford: Oxford University Press.

Colleoni, E., Rozza, A., \& Arvidsson, A. (2014). Echo chamber or public sphere? Predicting political orientation and measuring political homophily in Twitter using big data. Journal of Communication, 64(2), 317-332.

Curran, J., Fenton, N., \& Freedman, D. (2012). Misunderstanding the internet. New York, NY: Routledge.

Dahlgren, P. (2013). The political web. New York, NY: Palgrave Macmillan.

Davenport, T., \& Beck, J. (2001). The attention economy: Understanding the new currency of business. Boston, MA: Harvard Business School Press.

Dubois, E., \& Blank, G. (2018). The echo chamber is overstated: The moderating effect of political interest and diverse media. Information, Communication \& Society, 21(5), 729-745.

Flaxman, S., Goel, S., \& Rao, J. (2016). Filter bubbles, echo chambers, and online news consumption. Public Opinion Quarterly, 80(1), 298-320.

Garrett, R. (2009). Echo chambers online?: Politically motivated selective exposure among Internet news users. Journal of Computer-Mediated Communication, 14(2), 265-285.

Guallar, J., Suau, J., Ruiz-Caballero, C., Sáez, A., \& Masip, 
P. (2016). Re-dissemination of news and public debate on social networks. El Profesional de la Información, 25(3), 358-366.

Hallin, D., \& Mancini, P. (2004). Comparing media systems: Three models of media and politics. Cambridge: Cambridge University Press.

Hirzalla, F., van Zoonen, L., \& de Ridder, J. (2010). Internet use and political participation: Reflections on the mobilization/normalization controversy. The Information Society, 27(1), 1-15.

Holbert, R., Garrett, R., \& Gleason, L. (2010). A new era of minimal effects? A response to Bennett and lyengar. Journal of Communication, 60(1), 15-34.

Humanes, M. (2014). Exposición selectiva y partidismo de las audiencias en España [Selective exposure and partisanship in Spain]. Palabra Clave, 17(3), 773-802.

Humanes, M. (2016). Exposición selectiva, partidismo y polarización de las audiencias de los medios en España [Selective exposure, partisanship, and media audience polarisation in Spain]. In A. Casero (Ed.), Periodismo y democracia en el entorno digital [Journalism and democracy in the digital environment] (pp. 37-52). Madrid: SEP.

IAB. (2017). VIII estudio anual de redes sociales en España [VII annual report on social media in Spain]. Madrid: IAB. Retrieved from http://iabspain.es/wpcontent/uploads/iab_estudioredessociales_2017_ vreducida.pdf

Iyengar, S., \& Hahn, K. (2009). Red media, blue media: Evidence of ideological selectivity in media use. Journal of Communication, 59(1), 19-39.

Jamieson, K., \& Cappella, J. (2008). Echo chamber: Rush Limbaugh and the conservative media establishment. Oxford: Oxford University Press.

Khaldarova, I., \& Pantti, M. (2016). Fake news. Journalism Practice, 10(7), 891-901.

Klinger, U., \& Svensson, J. (2015). The emergence of network media logic in political communication: A theoretical approach. New Media \& Society, 17(8), 1241-1257.

Knobloch-Westerwick, S., Johnson, B., \& Westerwick, A. (2013). To your health: Self-regulation of health behavior through selective exposure to online health messages. Journal of Communication, 63(5), 807-829.

Lacour, M. (2015). A balanced news diet, not selective exposure: Evidence from a direct measure of media exposure. Paper presented at the APSA 2012 Annual Meeting, New Orleans, LA.

Lanham, R. (2006). The economics of attention: Style and substance in the age of information. Chicago, IL: University of Chicago Press.

Lazarsfeld, P., Berelson, B., \& Gaudet, H. (1948). The people's choice: How the voter makes up his mind in a presidential campaign. New York, NY: Columbia University Press.

Lord, C., Ross, L., \& Lepper, M. (1979). Biased assimilation and attitude polarization: The effects of prior theories on subsequently considered evidence. Journal of Personality and Social Psychology, 37(11), 2098-2109.

Masip, P., Ruiz, C., \& Suau, J. (2017). Monitoring media pluralism in Europe: Application of the media pluralism monitor 2017 in the European Union, FYROM, Serbia \& Turkey. Country report: Spain. Florence: Centre for Media Pluralism and Media Freedom. Retrieved from https://cadmus.eui.eu/ bitstream/handle/1814/61157/2018_Spain_EN.pdf

Masip, P., Suau, J., \& Ruiz, C. (2018). Questioning the selective exposure to news: Understanding the impact of social networks on political news consumption. American Behavioral Scientist, 62(3), 300-319.

Messing, S., \& Westwood, S. (2012). Selective exposure in the age of social media: Endorsements trump partisan source affiliation when selecting news online. Communication Research, 41(8), 1042-1063.

Mitchell, A. (2014). State of news media. Washington, DC: Pew Research Center.

Mitchell, A., Kiley, J., Gottfried, J., \& Guskin, E. (2013). The role of news on Facebook. Washington, DC: Pew Research Center.

Mitchelstein, E., \& Boczkowski, P. (2010). Online news consumption research: An assessment of past work and an agenda for the future. New Media \& Society, 12(7), 1085-1102.

Mouffe, C. (2013). Agonistics. London: Verso.

Munro, G. D., Ditto, P. H., Lockhart, L. K., Fagerlin, A., Gready, M., \& Peterson, E. (2002). Biased assimilation of sociopolitical arguments: Evaluating the 1996 U.S. presidential debate. Basic and Applied Social Psychology, 24(1), 15-26.

Newman, N., Fletcher, R., Kalogeropoulos, A., \& Nielsen, R. K. (2019) Reuters Institute digital news report 2019. Oxford: Reuters Institute.

Newman, N., Fletcher, R., Kalogeropoulos, A., Levy, D. A. L., \& Nielsen, R. K. (2017). Reuters Institute digital news report 2017. Oxford: Reuters Institute.

Pariser, E. (2011). The filter bubble: What the Internet is hiding from you. London: Penguin.

Press, A., \& Williams, B. (2010). The new media environment: An introduction. Oxford: Wiley-Blackwell.

Prior, M. (2007). Post-broadcast democracy. Cambridge: Cambridge University Press.

Prior, M. (2013). Media and political polarization. Annual Review of Political Science, 16, 101-127.

Purcell, K., Rainie, L., \& Mitchell, A. (2010). Understanding the participatory news consumer. Washington, DC: Pew Research Center. Retrieved from http://www.pewinternet.org/2010/03/01/ understanding-the-participatory-news-consumer

Roses, S. (2011). Confianza en la institución de los medios [Trust in media institutions]. Razón y Palabra, 2011(76). Retrieved from http://www. razonypalabra.org.mx/N/N76/varia/5a\%20entrega/ 48_Roses_V76.pdf

Ruiz, C., Domingo, D., Mico, J. L., Díaz-Noci, J., Meso, 
K., \& Masip, P. (2011) Public sphere 2.0? The democratic qualities of citizen debates in online newspapers. The International Journal of Press/Politics, 16(4), 463-487.

Schrøder, K. C. (2015). News media old and new. Journalism Studies, 16(1), 60-78.

Singer, J. (2013). User-generated visibility: Secondary gatekeeping in a shared media space. New media and Society, 16(1), 55-73.

Stroud, N. (2011). Niche news: The politics of news choice. Oxford: Oxford University Press.

Sunstein, C. (2002). Republic.com. Princeton, NJ: Princeton University Press.

Sunstein, C. (2009). Going to extremes: How like minds unite and divide. Oxford: Oxford University Press.
Sunstein, C. (2018). \#Republic: Divided democracy in the age of social media. Princeton, NJ: Princeton University Press.

Thorson, K., \& Wells, C. (2016). Curated flows: A framework for mapping media exposure in the digital age. Communication Theory, 26(3), 309-328.

Valera-Ordaz, L. (2018). Medios, identidad nacional y exposición selectiva: Predictores de preferencias mediáticas de los catalanes [Media, national identity and selective exposure: Predictors of media preferences by Catalans]. Revista Española de Investigaciones Sociológicas, 164, 135-154.

Zillmann, D., \& Bryant, J. (1985). Selective exposure to communication. Hillsdale, NJ: Lawrence Erlbaum.

\section{About the Authors}
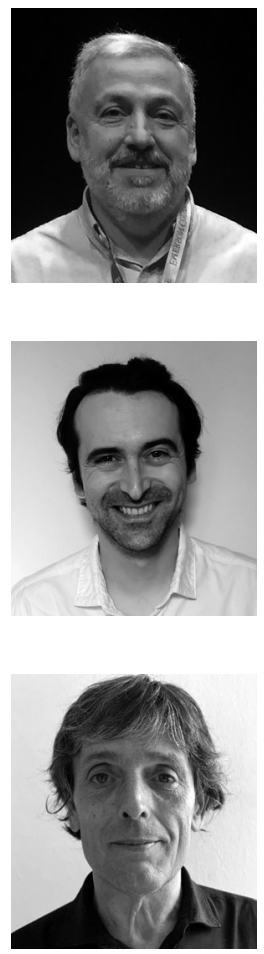

Pere Masip is Associate Professor at the Blanquerna School of Communication and International Relations at the Ramon Llull University (Barcelona, Catalonia). His research interests centre on the impact of technology on journalistic and communication practices. He has participated in several national and international projects. He is currently coordinating a research project funded by the Spanish Ministry of Economy and Competitiveness entitled "News consumption, social networks and pluralism in the hybrid media system" as well as the research "What's up with news? Fighting misinformation on WhatsApp: Users' approach," funded by Facebook/WhatsApp.

Jaume Suau (PhD) is a Professor at Ramon Llull University, based in Barcelona. As a member of the Digilab research group he has been Project Manager of MedMedia, as well as a member of the Media Pluralism Monitor, projects funded by the European Commission. His research interests are audience studies, news consumption, and trust in news, as well as media regulation and media development.

Carlos Ruiz-Caballero holds a PhD in Journalism and he is a Professor at the Blanquerna School of Communication and International Relations at the Ramon Llull University. His main research interests are media convergence, digital journalism, and active audiences from the perspective of the ethics of communication. He was awarded the Josep Vallverdú 2014 essay award for the book The Digitization of the Other. He is the author of La Agonía del Cuarto Poder, Prensa Contra Democracia (Trípodos, 2008). 